\title{
Follow-Up and Follow-Through of Depressed Patients in Primary Care: The Critical Missing Components of Quality Care
}

\author{
Leif I. Solberg, MD, Michael A. Trangle, MD, and Arthur P. Wineman, MD
}

Certainly we could improve our identification, diagnosis, and initial treatment approaches to the large numbers of depressed patients we see in primary care. However, until we have established the kind of systematic follow-up and follow-through that the US Preventive Services Task Force said is a prerequisite for its recommendation to routinely screen for depression, none of these earlier actions will make much difference. Recently, a number of controlled trials of innovative approaches to care management have demonstrated clearly how much patient outcomes are improved when systematic follow-up is in place. The problem is that there are few examples of such systems in real clinical practices. This article describes the main components of such a systematic approach. (J Am Board Fam Pract 2005;18:520-7.)

In 2002, the US Preventive Services Task Force published its first evidence-based recommendation for screening primary care patients for depression. ${ }^{1}$ It said that there was now B level evidence that screening adults for depression was effective. However, it also added an important caveat to this recommendation that it has not included in any other recommendations. This caveat was "clinical practices that screen for depression should have systems in place to ensure that positive screening results are followed by accurate diagnosis, effective treatment, and careful follow-up. Benefits from screening are unlikely to be realized unless such systems are functioning well."

There is good reason for this admonition. In their summary of the quality of health care of US adults, McGlynn and colleagues found that only $58 \%$ of 14 care process indicators of quality care for depression were satisfied. ${ }^{2}$ The National Committee for Quality Assurance (NCQA) recently published its 2004 review of the HEDIS (health plan employer data and information set) scores from health plans across the country. ${ }^{3}$ It noted that, "Since NCQA began tracking antidepressant med-

Submitted 14 January 2005; revised 2 June 2005; accepted 5 July 2005.

From HealthPartners Medical Group and Clinics, Minneapolis, $\mathrm{MN}$.

Conflict of interest: none declared.

Corresponding author: Leif I. Solberg, MD, HealthPartners Research Foundation, PO Box 1524, MS\#21111R, Minneapolis MN 55440-1524 (e-mail: leif.i.solberg@ healthpartners.com). ication management, rates have remained largely unchanged—and the gap between high performers and low has remained significant." HEDIS tracks 3 measures for new treatment with antidepressants for depression:

1. $61 \%$ stayed on antidepressant medication for at least 3 months.

2. $44 \%$ stayed on antidepressant medication for at least 6 months.

3. $20 \%$ had at least 3 clinician contacts in the first 3 months of antidepressant use.

These rates were significantly lower for patients on Medicare or Medicaid. It concluded that "an estimated 2.5 million depression-related sick days could be prevented if everyone were enrolled in a health plan that performed at the 90th percentile."

Fortunately, there have been many randomized controlled trials of depression care in primary care in the last 10 years that demonstrate clearly what is needed to improve depression management. ${ }^{4-18}$ The excellent systematic review of Gilbody et al provides a good summary of most of these trials, and Oxman et al provided a practical summary in what they called a 3-component model that is very consistent with the recommendations in this article. ${ }^{19,20}$ Wagner editorialized that "the type of treatment matters less than ensuring it is done properly and followed up." ${ }^{21}$ The key care concepts these trials have demonstrated to be effective are: 
1. Care management by a nonphysician working with the primary care physician

2. Planned collaborative care between physicians and mental health clinicians

3. Education and support of patients for selfmanagement

4. Attention to patient preferences

Although critical to good care management, these approaches are missing in nearly all primary care settings, and their potential is invisible to most clinicians. They can be implemented through "carve-out" disease management programs, but the many randomized trials cited above demonstrate that excellent results can be obtained in primary care if the above concepts are incorporated in a redesigned care process. The rest of this article will describe how these concepts can be implemented in practice through systems thinking and team care.

\section{What Is Primary Care of Depression Like?}

To better understand current primary care of adult patients with depression, we studied 274 patients in our medical group. ${ }^{22}$ Our care system has many advantages for depression care because all our patients have good insurance coverage, psychiatrists and therapists are part of the medical group, and each primary care clinic has a mental health therapist onsite frequently for consultation, therapy, or collaborative care. Unlike most studies that conduct a questionnaire screening of all patients for depression, we identified the patients for this study from claims data because they had received a new diagnosis of depression from a primary care physician. We surveyed these patients soon after the initial visit and again 3 months later, and we audited their charts. Most patients were started on antidepressants, usually as their only therapy, with few reporting receiving educational or self-management information or recommendations and only half reporting a recommendation to see a mental health therapist (chart audits documented this recommendation only $13 \%$ of the time). Of those given a new depression medication, 67\% stopped taking it on their own because they were having side effects, no improvement, felt better, or felt they didn't really need it. Over the next 3 months, only $10 \%$ had 3 or more visits and nearly all the patients meeting this HEDIS quality criterion had those visits with the mental health thera- pist in the clinic rather than with the primary care clinician. Only $36 \%$ had one follow-up visit with a physician in the next 3 months, $12 \%$ had 2 visits, and $1 \%$ had 3 or more.

The original and 3-month surveys incorporated a set of questions about depression that allowed a severity score to be calculated to monitor the effectiveness of treatment. ${ }^{23}$ Seventy percent scored in the depression range initially and 50\% 3 months later, whereas only $48 \%$ reported their depression had improved and $16 \%$ reported it was worse. Understandably, only $34 \%$ of these patients reported being very satisfied with their depression care at baseline and 3 months. Dissatisfaction was linked with not being given a choice of treatments, feeling it was hard to see a mental health specialist, and disliking their follow-up care. If this is the case in a system with so many advantages, what must it be like elsewhere, especially for the majority of patients who have recurrent or chronic depression? ${ }^{24}$

These results are certainly not because primary care physicians have poor intentions. They chose primary care despite lower incomes because they enjoy helping people and having continuous healing relationships with patients and their families. However, the current medical care environment has steadily increasing expectations while providing payments in primary care that reward volume over quality and provide inadequate resources to improve, especially for small practices that are not part of large multispecialty care systems. The challenge is to find ways to improve care within those limitations while waiting for changes in the reimbursement system.

\section{Changes That Would Improve Our Results}

We don't need to guess about what changes would be helpful in improving care for these patients. Many randomized controlled trials over the past 10 years have identified the types of changes we should be making, and they are consistent with the recommendations of the Future of Family Medicine report. ${ }^{25}$ The most important change is implementing a care management role, and doing so under the supervision of the patient's primary care physician seems most likely to avoid fragmenting care. The key element in this role is proactive follow-up that includes monitoring depression status and initiating remedial action when adequate response is not being achieved. Other elements of the role are to 
assure that referrals, follow-up contacts, and use of educational and support resources occur as planned. These elements can be done well through systematic supportive follow-up telephone calls by nurses or other non-mental health professionals. Some studies have focused on just this change in care, whereas most others have included this approach as a fundamental part of a broader set of patient-centered changes. After Lynch showed that regular therapist calls supervised by a psychiatrist made a difference, other studies substituted a nurse working with the primary care physician, an approach that is much more feasible and acceptable in primary care. ${ }^{10,12,13,26}$ Hunkeler's trial showed that patients receiving nurse phone calls had greater improvement in their depression despite no change in adherence to antidepressant medications. ${ }^{13}$ Rost et al extended the nurse follow-up phone calls for 24 months on the assumption that most depression has chronic disease elements. ${ }^{27}$ The patients in their intervention group were $33 \%$ more likely to be in remission and they had $24 \%$ better mental function and $17 \%$ better physical function than those in the usual care group at 24 months.

The second change with clearly demonstrated benefit (but facilitated by the care management change described above) is increasing the likelihood that mental health specialists have a shared role in care when the patient prefers that or when alternate treatment approaches do not seem to be working well enough. The principal studies have been done by Katon et al, showing that when depression care is formally organized with preplanned consultation or shared care between the primary care physician and either a psychiatrist or an on-site psychologist, patient outcomes are better than usual care. ${ }^{6,28}$ Such shared care benefits have been found to be produced at little overall cost per patient. $^{29}$

Another desirable change is to improve education and support for patient self-management of this illness. This strategy has its own evidence base, but it also has been receiving increasing attention because the Institute of Medicine's report on "Crossing the Quality Chasm" highlighted patientcenteredness as one of the 6 aims for improving care. ${ }^{30}$ Stone et al reported a meta-analysis of 108 trials and found that strategies that involved patients in self-management of preventive services was one of the few approaches likely to make a difference. ${ }^{31}$ Glasgow, Von Korff, and others have demonstrated that this strategy is particularly important in chronic disease care. ${ }^{32,33}$ The Von Korff definition of this approach includes: (1) collaborative definition of problems, (2) targeting, goal setting, and planning, (3) self-management training and support services, (4) active and sustained follow-up. ${ }^{32}$ It was especially noted that this common core of services "need not be reinvented for each disease." A related benefit from any change that emphasizes patient self-management is the increased likelihood that patient preferences will be addressed, a need highlighted in Wagner's editorial about the key goals for improved depression care. ${ }^{21}$ Studies of the attitudes of depressed patients in primary care have consistently shown a desire for treatment, but with more preferring counseling than medications and few wanting to be shunted off to mental health professionals without a continuing involvement by their primary care physician. ${ }^{34-36}$ In most of the randomized trials of improved depression care, the care manager role is clearly focused on self-management support. . $^{911-13,16,27}$

Some of the above changes could be accomplished through a carve-out disease management program, and health plans are under increasing pressure to do that as the costs of health care keep increasing. ${ }^{37,38}$ However, the evidence from the trials demonstrates that they can all be implemented in primary care, building on the established relationship with the patient's primary care physician in a patient-centered way that seems likely to be better for all concerned. ${ }^{38,39}$ But doing that will require primary care physicians to make some serious changes in the way they provide care for these patients, preferably as part of a general reorganization of the approach to treating all patients with chronic diseases.

\section{Why Are There Problems?}

The apparent deficiencies in the primary care physicians' typical approach to treating their patients' depression problems do not seem to be because of unwillingness to accept responsibility for this problem, either in our medical group or in published surveys. ${ }^{40}$ Instead, they are part of the general problem with our approach to the care of patients with chronic conditions. For a variety of reasons, including training, tradition, busyness, and lack of sufficient resources and practice system support, we tend to treat each encounter with patients with 
chronic conditions as a separate episode with ourselves as the only significant resource and no plan for structured follow-up or ability to provide broad-based self-management support of our patients. ${ }^{41}$ We primary care physicians generally do not have the kind of team-based and systematic proactive approach to care that is needed by patients with chronic conditions and that is recommended in the Future of Family Medicine Report. ${ }^{25}$ Such a proactive team approach is especially needed for depressed patients who are less likely to adhere to treatment recommendations or take the initiative for self-care, and that is truer for those in primary care. ${ }^{42}$ Wagner and colleagues have provided extensive literature reviews of care innovations that have made a difference in the quality of care for patients with a variety of chronic conditions. ${ }^{33,41,43}$ These innovations are very similar to the important changes in care described above.

\section{The Chronic Care Model As a Guide}

Because significant changes in care approach are needed, it may be helpful to have a model for thinking about these changes in a comprehensive way. Fortunately, Wagner and many colleagues have also developed a conceptual model for organizing our thinking about chronic disease care. It is usually referred to as the Chronic Care Model (or sometimes the Planned Care Model), and it is illustrated in Figure 1. ${ }^{41,44,45}$ The key to the model is what is called productive interactions between a prepared practice team and an informed activated patient. To facilitate this, the clinic or medical group needs to develop and maintain at least 4 main components of the model in relation to depression care, along with the following systems in each:

1. Delivery System Design-Change from a physician-does-everything-except-prep-patients approach to a practice team where each physician works with a rooming assistant, nurse (ideally an $\mathrm{RN}$ ), and receptionist, each of whom has expanded defined roles. The key to a new way of behaving is having the nurse team member act as care manager, especially for patients with depression or other chronic diseases.

2. Clinical Information System-Establish a registry of all clinic patients with depression and use it to provide reminders to patients and team members about needed follow-up contacts and services. Add a patient-completed questionnaire to assess severity of depression periodically. Include the severity results in a flow sheet of care data in each patient's record and use the flow sheet to communicate among team members and to monitor the status of each patient's depression and care over time. All these changes can be made without an electronic record system, although having one makes it easier.

3. Decision Support-Before doing anything else, all physicians must agree on a clinic- or medical group-wide evidence-based guideline for depression care. Incorporate these guide-

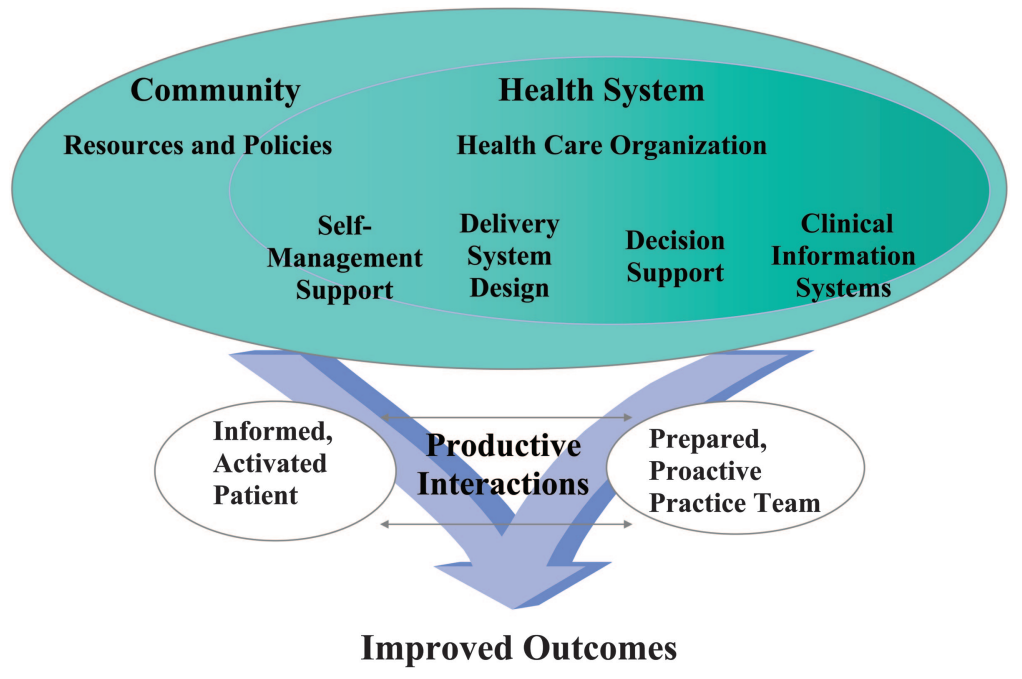

Figure 1. The Chronic Care Model (reprinted with permission of the American College of Physicians). ${ }^{44}$ 
lines into team member tasks, as well as in specifications for collaborative roles of mental health services during routine care. In addition, the practice should establish an agreement with mental health consultants on how to quickly access their advice or involvement when patient difficulties arise.

4. Self-Management Support-The goal is to provide all patients with as much information and resources as they want and need so that they can take on as active a role in their own care as they are willing to do. The team care manager is the key person here, providing information and advice during regularly scheduled follow-up contacts (usually by phone).

\section{What Would Systematic Care Management Look Like?}

The following description of a clinic system for depression care is intended to provide an example that can be modified to fit each clinic's unique situation and preferences. It assumes that there is some type of team that includes a nonphysician (usually a nurse) with the ability to provide patient self-management support (not mental health counseling) in a closely integrated way with the primary physician. The description also assumes that all the clinicians have agreed on a depression guideline (a good starter example is available from www.icsi. org) and a patient questionnaire that can validly assess the presence and severity of depression. Although there is little point in routine screening to identify more depressed patients until a clinic site has implemented a systematic approach to management of the patients already being diagnosed (as noted by the US Preventive Services Task Force), a depression questionnaire is still needed to clarify the diagnosis, establish severity, and monitor progress over time. Because the PHQ-9 is a good example of a questionnaire useful for those 3 purposes, and because it is increasingly becoming the standard, that is what will be used in the following example. ${ }^{46}$ The PHQ-9 has 9 questions, each of which covers one of the DSM-IV criteria for depression and is scored from 0 to 3 . Thus the maximum total score is 27 , and a score of 10 to 14 suggests moderate depression, 15 to 19 moderately severe, and 20 to 27 severe. This instrument has been well-validated for assessing diagnosis, severity, and outcomes, and can be thought of as similar to the HbA1c measure that has been so valuable for following and improving diabetes care. ${ }^{47-51}$

Care management begins after a clinician has identified a patient with depression using the PHQ-9 and after deciding on an initial approach to care based on review of the treatment and selfmanagement options together. The next steps might be:

1. Inclusion of this patient in a depression registry-this should follow automatically and not depend on the physician remembering to do so, therefore establishing a redundant system using either billing codes for depression or entry by any member of the care team.

2. Contact from the team nurse-usually by phone but also potentially during the initial visit if the physician introduces them and the nurse has time available.

3. Baseline assessment-assures that the patient has completed the PHQ-9 and gathers relevant information about the patient's living situation, health needs, and knowledge/attitudes about depression and its care. Key information such as the PHQ-9 score and primary symptoms is entered on a new depression flow sheet.

4. Initiation of self-management support-provides additional information about depression, treatment options, and medication side effects (if on meds), as well as additional resources for self-care and community help (eg, books, classes, support groups) and the general approach to be used for follow-up. A particularly important part of this is clarifying the usual delay in medication benefit, the need to stay on medication for at least 6 months, and how to handle emergency situations or relapse.

5. Facilitation of the selected treatment and selfmanagement-helps with referral arrangements and/or adjustment to medications, and checks on whether the treatment plan is being followed, including the encouragement of patient activation and self-management actions at every encounter.

6. Follow-up-before or soon after each visit with a clinician or as modified per individual patient needs and preferences, the nurse calls the patient to monitor severity (repeat PHQ-9 at each contact or at least every 3 to 6 months) and progress on the patient's self-management, treatment plan, and referrals. Rechecking on 
suicidal risks is a critical part of this follow-up, aided by one question on the PHQ-9. These contacts provide a wonderful opportunity to ask about how the patient is doing with making the cognitive or behavioral changes that were agreed on previously as important self-care contributors to reducing depression, and making new plans. Key parts of this information are entered on the flow sheet and, if more detail is needed, can go in a progress note in the chart.

7. Follow-through-this includes advising the physician if the patient is having trouble with the treatment plan or any referrals or follow-up visits, as well as informal status updates during the course of normal team communications. If a mental health clinician is also providing visit care, the nurse will usually be in the best position to coordinate needed information.

\section{Implementing Systematic Care Management}

Because of the resource and reimbursement limitations identified in the earlier section on current primary care of depression, many small practice settings may find it difficult to implement such a system. Because it is fully compatible with the changes recommended by the Future of Family Medicine, it should also be as financially feasible as those changes. ${ }^{25}$ However, systematic care can also be implemented in steps, starting with low cost items:

1. Agreement by all physicians in a practice on a clinical guideline for depression care

2. Simple audit of enough charts of depressed patients to verify that there are problems in desired follow-up and follow-through

3. Use the PHQ-9 in initial appraisal and followup visits as a way to measure severity and outcomes (think of it as of similar value to an A1c test for diabetes control)

If, as we suspect, many patients do not follow-up or have contacts limited to obtaining phone refills for antidepressants, any staff person (receptionist?) can use a simple manual tickler system to call patients who haven't made guideline- or physician-recommended follow-ups. Besides improving care, this will increase patient satisfaction and produce enough reimbursable follow-up visits to pay for the calls. Further details about training or materials used in the follow-up approach proven in the RAND trials (called Partners in Care) can be obtained from its website at http://www.rand.org/ health/pic.products/.

\section{Conclusion}

The physicians and clinics that decide to convert to such a systematic approach to care management for patients with depression and other chronic diseases will not find it easy. The differences from usual care are large for physicians, nurses, and patients alike. Therefore, the transition will require a lot of patience and working out many details that go beyond the scope of this article. However, the rewards for each of the participants can be great as well.

\section{References}

1. U.S. Preventive Services Task Force. Screening for depression: Recommendations and rationale. Ann Intern Med 2002;136:760-4.

2. McGlynn EA, Asch SM, Adams J, et al. The quality of health care delivered to adults in the United States. N Engl J Med 2003;348:2635-45.

3. National Committee for Quality Assurance. The state of health care quality 2004: industry trends and analysis. Washington (DC): National Committee for Quality Assurance, 2004:22.

4. Katon W, Robinson P, Von Korff M, et al. A multifaceted intervention to improve treatment of depression in primary care. Arch Gen Psychiatry 1996;53: 924-32.

5. Katon W, Rutter CM, Ludman EJ, et al. A randomized trial of relapse prevention of depression in primary care. Arch Gen Psychiatry 2001;58:241-7.

6. Katon W, Von Korff M, Lin E, et al. Collaborative management to achieve depression treatment guidelines. J Clin Psychiatry 1997;58:20-3.

7. Katon W, Von Korff M, Lin E, et al. Populationbased care of depression: effective disease managment strategies to decrease prevalence. Gen Hosp Psychiatry 1997;19:169-78.

8. Katzelnick DJ, Simon G, Pearson SD, et al. Randomized trial of a depression management program in high utilizers of medical care. Arch Fam Med 2000;9:345-51.

9. Simon G, Von Korff M, Rutter CM, Wagner E. Randomised trial of monitoring, feedback, and management of care by telephone to improve treatment of depression in primary care. BMJ 2000;320:550-4.

10. Rubenstein LV, Jackson-Triche M, Unutzer J, et al. Evidence-based care for depression in managed primary care practices. Health Aff 1999;18:89-105.

11. Wells KB, Sherbourne C, Schoenbaum M, et al. Impact of disseminating quality improvement programs for depression in managed primary care: a 
randomized controlled trial. JAMA 2000;283:21220.

12. Rost K, Nutting P, Smith J, Werner J, Duan N. Improving depression outcomes in community primary care practice: a randomized trial of the quEST intervention. J Gen Intern Med 2001;16:143-9.

13. Hunkeler EM, Meresman JF, Hargreaves WA, et al. Efficacy of nurse telehealth care and peer support in augmenting treatment of depression in primary care. Arch Fam Med 2000;9:700-8.

14. Dwight-Johnson M, Unutzer MJ, Sherbourne C, Tang L, Wells KB. Can quality improvement programs for depression in primary care address patient preferences for treatment? Med Care 2001;39:93444.

15. Unutzer J, Katon W, Callahan CM, et al. Collaborative care management of late-life depression in the primary care setting: a randomized controlled trial. JAMA 2002;288:2836-45.

16. Dietrich AJ, Oxman TE, Williams JR Jr., et al. Reengineering systems for the treatment of depression in primary care: cluster randomised controlled trial. BMJ 2004;329:602-7.

17. Simon GE, Ludman EJ, Tutty S, Operskalski B, Von Korff $M$. Telephone psychotherapy and telephone care management for primary care patients starting antidepressant treatment: a randomized controlled trial. JAMA 2004;292:935-42.

18. Bruce ML, Ten Have TR, Reynolds CF, et al. Reducing suicidal ideation and depressive symptoms in depressed older primary care patients: a randomized controlled trial. JAMA 2004;291:1081-91.

19. Gilbody S, Whitty P, Grimshaw J, Thomas R. Educational and organizational interventions to improve the management of depression in primary care: a systematic review. JAMA 2003;289:3145-51.

20. Oxman TE, Dietrich AJ, Williams JW Jr., Kroenke K. A 3-component model for reengineering systems for the treatment of depression in primary care. Psychosomatics 2002;43:441-50.

21. Wagner EH. Managing depression in primary care: the type of treatment matters less than ensuring it is done properly and followed up. BMJ 2001;322: 746-7.

22. Solberg LI, Fischer LR, Rush WA, Wei F. When depression is the diagnosis, what happens to patients and are they satisfied?. Am J Manag Care 2003;9: 131-40.

23. Kohout FJ, Berkman LF, Evans DA, Cornoni-Huntley J. Two shorter forms of the CES-D depression symptoms index. J Aging Health 1993;5:179-93.

24. Judd LL. The clinical course of unipolar major depressive disorders. Arch Gen Psychiatry 1997;4:98991.

25. Martin JC, Avant RF, Bowman MA, et al. The future of family medicine: a collaborative project of the family medicine community. Ann Fam Med 2004;(2 Suppl 1):S3-32.
26. Lynch DJ, Tamburrino MB, Nagel R. Telephone counseling for patients with minor depression: preliminary findings in a family practice setting. J Fam Pract 1997;44:293-8.

27. Rost K, Nutting P, Smith JL, Elliott CE, Dickinson $M$. Managing depression as a chronic disease: a randomised trial of ongoing treatment in primary care. BMJ 2002;325:934-9.

28. Katon W, Von Korff M, Lin E, et al. Collaborative management to achieve treatment guidelines: impact on depression in primary care. JAMA 1995;273:102631.

29. Simon GE, Katon WJ, Von Korff M, et al. Costeffectiveness of a collaborative care program for primary care patients with persistent depression. Am J Psychiatry 2001;158:1638-44.

30. Institute of Medicine. Crossing the Quality Chasm: A New Health System for the 21st Century. Washington (DC): National Academy Press, 2001.

31. Stone EG, Morton SC, Hulscher ME, et al. Interventions that increase use of adult immunization and cancer screening services: a meta-analysis. Ann Intern Med 2002;136:641-51.

32. Von Korff M, Gruman J, Schaefer J, Curry SJ, Wagner EH. Collaborative management of chronic illness. Arch Intern Med 1997;127:1097-102.

33. Glasgow RE, Funnell MM, Bonomi AE, Davis C, Beckham V, Wagner EH. Self-management aspects of the improving chronic illness care breakthrough series: implementation with diabetes and heart failure teams. Ann Behav Med 2002;4:80-7.

34. Kadam UT, Croft P, McLeod J, Hutchinson M. A qualitative study of patients' views on anxiety and depression. Br J Gen Pract 2001;51:375-80.

35. Brody DS, Khalia AA, Thompson TL. Patients' perspectives on the management of emotional distress in primary care settings. J Gen Intern Med 1997;12: 403-6.

36. Dwight-Johnson D, Sherbourne CD, Liao D, Wells $\mathrm{KB}$. Treatment preferences among depressed primary care patients. J Gen Intern Med 2000;15:52734.

37. Aubert RE, Fulop G, Xia F, Thiel M, Maldonato D, Woo C. Evaluation of a depression health management program to improve outcomes in first or recurrent episode depression. Am J Manag Care 2003; 9:374-80.

38. Wagner EH. The role of patient care teams in chronic disease management. BMJ 2000;320:56972.

39. Bodenheimer T. Disease management-promises and pitfalls. N Engl J Med 1999;340:1202-5.

40. Williams JW Jr, Rost K, Dietrich AJ, Ciotti MC, Zyzanski SJ, Cornell J. Primary care physicians' approach to depressive disorders. Effects of physician specialty and practice structure. Arch Fam Med 1999;8:58-67.

41. Wagner EH, Austin BT, Von Korff M. Organizing 
care for patients with chronic illness. Milbank Q 1996;74:511-44.

42. Van Voorhees BW, Cooper LA, Rost KM, et al. Primary care patients with depression are less accepting of treatment than those seen by mental health specialists. J Gen Intern Med 2003;18:9911000 .

43. Wagner EH, Austin BT, Von Korff M. Improving outcomes in chronic illness. Manag Care Q 1996;4: $12-25$.

44. Wagner EH. Chronic disease management: what will it take to improve care for chronic illness? Eff Clin Pract 1998;1:2-4.

45. Wagner EH, Davis C, Schaefer J, Von Korff M, Austin BT. A survey of leading chronic disease management programs: are they consistent with the literature?. Manag Care Q 1999;7:56-66.

46. Kroenke K, Spitzer RL, Williams JBW. The PHQ-9: Validity of a brief depression severity measure. J Gen Intern Med 2001;16:606-13.

47. Lowe B, Unutzer J, Callahan CM, Perkins AJ,
Kroenke K. Monitoring depression treatment outcomes with the patient health questionnaire-9. Med Care 42:1194-201.

48. Lowe B, Spitzer RL, Grafe K, et al. Comparative validity of three screening questionnaires for DSM-IV depressive disorders and physicians' diagnoses. J Affect Disord 2004;78:131-40.

49. Lowe B, Grafe K, Zipfel S, Witte S, Loerch B, Herzog W. Diagnosing ICD-10 depressive episodes: superior criterion validity of the Patient Health Questionnaire. Psychother Psychosom 2004;73: 386-90.

50. Rief W, Nanke A, Kaiberg A, Braehler E. Base rates for panic and depression according to the Brief $\mathrm{Pa}$ tient health Questionnaire (Brief PHQ). A population based study. J Affect Disord 2004;82:271-6.

51. Lowe B, Kroenke K, Herzog W, Grafe K. Measuring depression outcome with a brief self-report instrument: sensitivity to change of the Patient Health Questionnaire (PHQ-9). J Affect Disord 2004;81: 61-6. 